\title{
Smart Boilers: Grid Support Services from Non-Critical Loads
}

\author{
Panagis N. Vovos ${ }^{1}$, Konstantinos G. Georgakas ${ }^{2}$ \\ ${ }^{1}$ Department of Electrical and Computer Engineering, University of Patras, University Campus, Rio, Greece \\ ${ }^{2}$ Department of Electrical and Computer Engineering, University of the Peloponnese, Patras, Greece \\ Email: panagis@upatras.gr
}

How to cite this paper: Vovos, P.N. and Georgakas, K.G. (2020) Smart Boilers: Grid Support Services from Non-Critical Loads. Journal of Power and Energy Engineering, 8, 23-45.

https://doi.org/10.4236/jpee.2020.812003

Received: November 24, 2020

Accepted: December 26, 2020

Published: December 29, 2020

Copyright $\odot 2020$ by author(s) and Scientific Research Publishing Inc. This work is licensed under the Creative Commons Attribution International License (CC BY 4.0).

http://creativecommons.org/licenses/by/4.0/ (c) (i) Open Access

\begin{abstract}
The aim of this paper is to present the concept of a simple and cheap upgrade for electric water boilers, allowing them to provide power quality services to the distribution grid. The upgrade requires only minimum additional hardware and it is easily installable. "Smart Boilers", as the upgraded boilers are named, perform precise active and reactive power control, but most significantly mitigate line current harmonics. Active and reactive power control is implemented by appropriate regulation of the modulation sinewave amplitude and phase, respectively. This type of control is easily customizable in order to accommodate a variety of power quality targets, depending on the required level of services and available grid monitoring equipment. The method used for line current harmonic compensation is based on the injection of mirror harmonics created at the modulation stage of the converter. It is indifferent of harmonic source: it is equally successful at mitigating harmonics caused by the power electronic converter of the Smart Boiler, other sources of current harmonics or loads. The achieved grid services are clearly beyond the "on/off" operation of electric boilers, currently implemented by Demand Side Management (DSM) in order to shift load away from peak hours. It has been demonstrated through simulations, that Smart Boilers can assist voltage regulation at terminal buses, compensate reactive power and suppress harmonic currents at lines.
\end{abstract}

\section{Keywords}

Electrical Grid Improvement, High Harmonics Minimization, Smart Boilers, Smart Power Grids, Active Power Control, Reactive Power Compensation

\section{Introduction}

Renewable Energy Sources (RES) have long started penetrating the distribution 
grid, turning domestic consumers of electricity to producers [1]. Passive distribution grids had to become smarter, in order to maintain an acceptable level of reliability and quality of supply, while handling power from intermittent and unpredictable local sources [2]. Energy storage seems like a viable future solution to RES variability and unpredictability of supply [3]. However, it is still quite expensive to buy and maintain, especially, for small scale applications suitable for distribution grids [4]. Li-ion batteries, currently the most practical option, have a questionable environmental impact with their 10-year long life span and negligible recyclability. More widespread, environmental friendly and long-lasting solutions are definitely needed.

The task becomes easier, though, when there is some assistance from the side of the demand. Demand-Side Management (DSM) encourages consumers to use less energy during peak hours, or to shift the time of energy use to off-peak times, such as night-time and weekends [5]. Direct load control of residential appliances has already been examined [6]. However, this type of control is always limited at shifting blocks of active power (i.e. the nominal power of each participating appliance) to more favorable time periods. The electric boiler specifically, as one of the most power-consuming, but non-critical, domestic load is already used in DSM to shift load from peak hours to hours of low demand. Furthermore, it is potentially an energy storage device (thermal) already installed in most houses around the world. In [7], the "on/off" operation of electric boilers is directly controlled by the grid operator in order to reduce overall demand variations, taking into account the base load. The significant financial value of such services, as well as, the possibility of creating a market mechanism that will compensate end-users for the automatic participation of their domestic thermal appliances on DSM is examined in [8]. However, the financial value could be drastically increased if a) DSM had more precise control over boilers' power (not just on/off operation) and b) additional services could be provided to the grid during their operation.

In this work, we present a new application for the electric boiler. With the addition of an inexpensive controlled bridge rectifier at the boiler supply line, it can be converted to a voltage support and harmonic compensation tool for the network operator while heating water. The load shifting capability for DSM is also improved, since the simple on/off switching operation, suggested in [7], is replaced by full and continuous control of the exact power (thus heating) consumed by the boiler. Therefore, this application for the electric boiler will make it smarter than a controllable on/off dump load as utilized under current DSM practice; so, let it be called "Smart Boiler" from now on. Such properties, targeting the improvement of the quality of supply, become requirements for the infrastructure of smart grids [9]. Currently, the only controllable domestic devices that are considered for the provision of such Smart Grid services (reactive power or harmonics compensation), are based on battery storage or RES, which are definitely not as common and inexpensive as boilers [10]. On the contrary, the 
widespread installation of Smart Boilers offering such services to the grid is expected to have a significant social and financial value at a minimum cost. However, this value is yet to be properly assessed and it will be the target of future work.

A Smart Boiler is, basically, a typical electric boiler tank, except that power supplied to the heating resistor is controlled by a simple power electronic device. Power control, voltage support and harmonic compensation are achieved by appropriate control of that device, while heating the water in the tank. Since, the boiler tank remains practically the same, existing typical boilers could be upgraded by the addition of the control device on the switchboard, in series with the existing Micro Circuit Breaker (MCB), or on the connection box next to the boiler. This means that every household with an electric boiler or solar boiler, which also contains resistors for auxiliary power when there is little sun, could potentially be converted to a controllable endpoint for the support of the smartgrid. Obviously, the bigger the energy/water tank the longer and higher the support to the grid. Therefore, the application of Smart Boilers could be extended to larger energy systems with even greater thermal inertia, e.g. provide part of the energy needed for central heating. The target of this work is limited to proving the operational capabilities of the suggested device. Other applications for domestic or even industrial purposes should also be investigated, so that the full potential of the suggested device is exploited.

The use of non-critical loads for grid support has been examined in [11]. In that work, a power electronic converter regulates the power supplied from an autonomous grid to a non-critical load, in order to provide dynamic frequency support. Also, current harmonics created from the operation of the converter are reduced due to appropriate modulation, minimizing the need for additional hardware, such as active or passive filters. On the contrary, this work suggests an active power control for voltage regulation in interconnected Low Voltage (LV) grids. Furthermore, harmonic compensation from Smart Boilers mitigates distortion of line currents indifferent of their source; i.e. the operation of the converter or other harmonic sources. Additionally, it is recognized by the authors in [11], that their harmonic compensation method is less effective when the operation of the converter diverges from a favorable duty cycle. As it will be demonstrated, this is not the case with the Smart Boilers. Finally, Smart Boilers provide reactive power support to the grid, which is not investigated and cannot be provided by their approach. Therefore, Smart Boilers serve different purposes and experience better performance.

The paper has the following structure. First, the topology and characteristics of the Smart Boiler hardware are described, followed by a description of the control methodology (Section 2). Later, the theory behind power control and harmonic compensation implemented by the Smart Boiler is presented (Section 3). The implementation of the theory in terms of Smart Boiler's converter modulation is presented in Section 4. In Section 5, the capability of the Smart Boiler to 
offer significant power quality services to the smart grid, by appropriate control of active and reactive power, and suppression of grid current harmonics is demonstrated. For this purpose, a typical distribution system is used as a test bed: a Medium Voltage (MV) supply line provides power to LV feeders for a mixture, in terms of type and size, of loads. Future research work and possible applications of the suggested system are indicated in Section 6. A summary of the most important conclusions, together with limitations for the Smart Boiler conclude the paper (Section 7).

\section{Smart Boiler Hardware}

A typical electric boiler, basically, consists of a well-insulated water tank containing a resistor and a thermostat. When the user wants to warm up water closes the switch of an $\mathrm{MCB}$ and power from the $\mathrm{AC}$ mains is supplied directly to the resistor in the tank. If the maximum acceptable temperature is reached (usually $60^{\circ} \mathrm{C}$ ) the thermostat disconnects the resistor from the supply, until the water temperature drops again below a lower threshold temperature. The user can stop the heating process anytime by opening the switch of the MCB. When electric boilers are used in DSM, manual MCB operation is replaced by a remotely controlled power switch. The switch usually follows a time-plan of operation outside peak-demand hours, in order to maintain water temperature at an acceptable level during hot water consumption hours, utilizing the good heat insulating properties of the water tank.

A Smart Boiler is, basically, a typical electric boiler tank, except that power supplied to the heating resistor is controlled by a simple diode rectifier bridge in series with a switching device, for example an IGBT (Figure 1). Active and reactive power control, as well as harmonic compensation, are achieved by appropriate triggering of this single switching device. More specifically, a microcontroller collects a) the required sensor readings, locally, from the hardware upgrade (e.g. supplying line current) and b) the requests for services by the grid operator, over any available telecommunication infrastructure (e.g. the internet), in order to implement the appropriate control on pulse modulation, as described in detail in the next Section. Since the additional hardware is connected between the AC supplying line and the boiler, practically any typical electric boiler can be upgraded to a Smart Boiler. The additional hardware can be mounted at the switchboard after the MCB (Figure 2(a)) or at the point of connection of the supplying line to the boiler (Figure 2(b)).

\section{Smart Boiler Control}

In this Section, the control of the Smart Boiler will be explained. Three modulation strategies are simultaneously applied on the single switching device of the power converter interfacing the electric boiler with the mains, in order to assist the smart grid in achieving three relevant targets: active power control, reactive power control and harmonic compensation. Depending on the characteristics of 
the distribution feeder $(\mathrm{R}, \mathrm{X})$, active or/and reactive power control can be used for voltage regulation. Compensation of harmonic currents is achieved by appropriate injection of mirror harmonics. A detailed description of the three modulation strategies can be found in the following three subsections.

\subsection{Active Power Control}

Active power $P$ consumed on resistor $R$ of the electric boiler is given by the following fundamental equation:

$$
P=V_{b}^{2} / R \text {, }
$$

where $V_{b}$ is the RMS value of the voltage applied on the resistor.

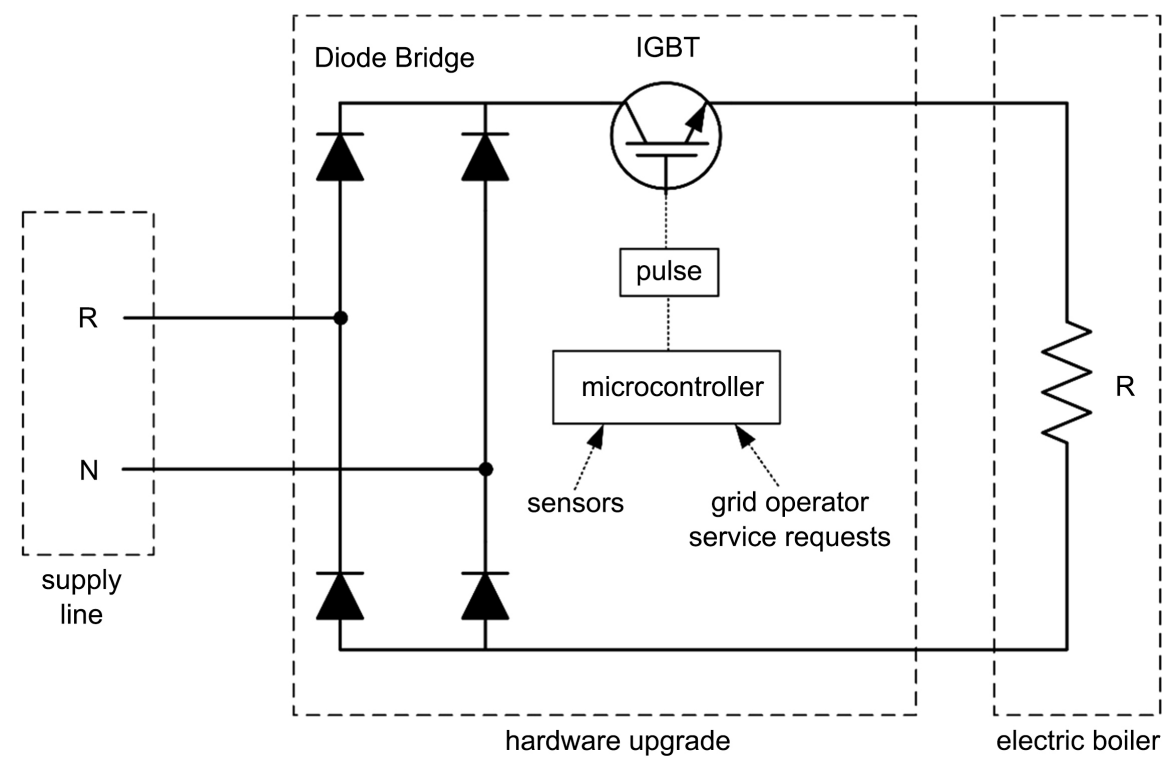

Figure 1. Topology of hardware for the upgrade of electric boilers to Smart Boilers.

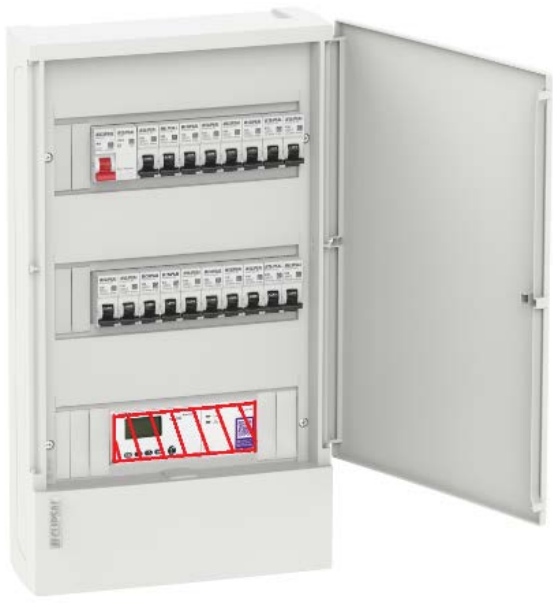

(a)

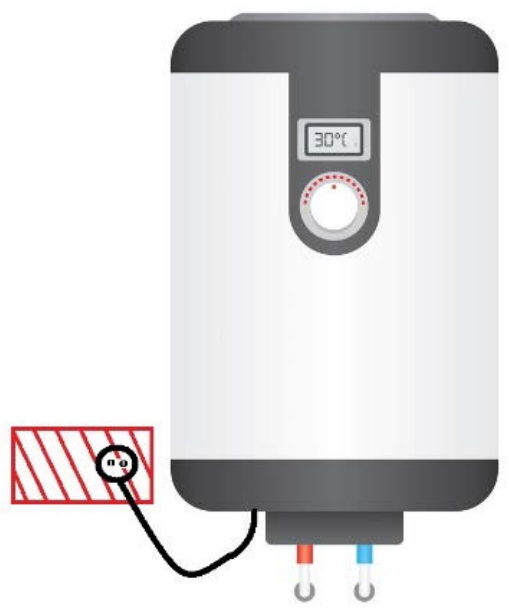

(b)

Figure 2. Possible connection points (hatched) of hardware upgrade, (a) at the switchboard next to the MCB of the boiler, (b) at the connection point of the supply line to the boiler. 
$V_{b}$ can be controlled by appropriate Pulse Width Modulation (PWM) of the rectifier's single switching element. A rectified sinewave signal, synchronized with the AC voltage supply, is compared with a triangular signal having the same frequency with the desirable switching frequency. When the triangular waveform is lower than the rectified sinewave the switching element is triggered and the rectified input AC voltage is applied on the resistor (Figure 3). The ratio of sinewave magnitude over the triangular waveform magnitude is called magnitude modulation ratio $\left(m_{a}\right)$. By regulating $m_{a}$, the RMS value of the output voltage $\left(V_{b}\right)$ can be controlled. According to (1), control of $V_{b}$ is directly connected with the control of active power consumed on the resistor of the electric boiler. The operation of the circuit presented in Figure 1 has been simulated and $V_{b}^{2}$ has been measured with respect to $m_{a}$. Figure 4 contains the plot of $V_{b}^{2}$ with respect to $m_{a} \cdot V_{b}^{2}$ is calculated as a percentage of $V_{b}^{2}$ for $m_{a}=1$. Obviously, there is a linear relationship between $m_{a}$ and $V_{b}^{2}$, thus, there is a linear relationship between $m_{a}$ and active power $P$, according to (1).

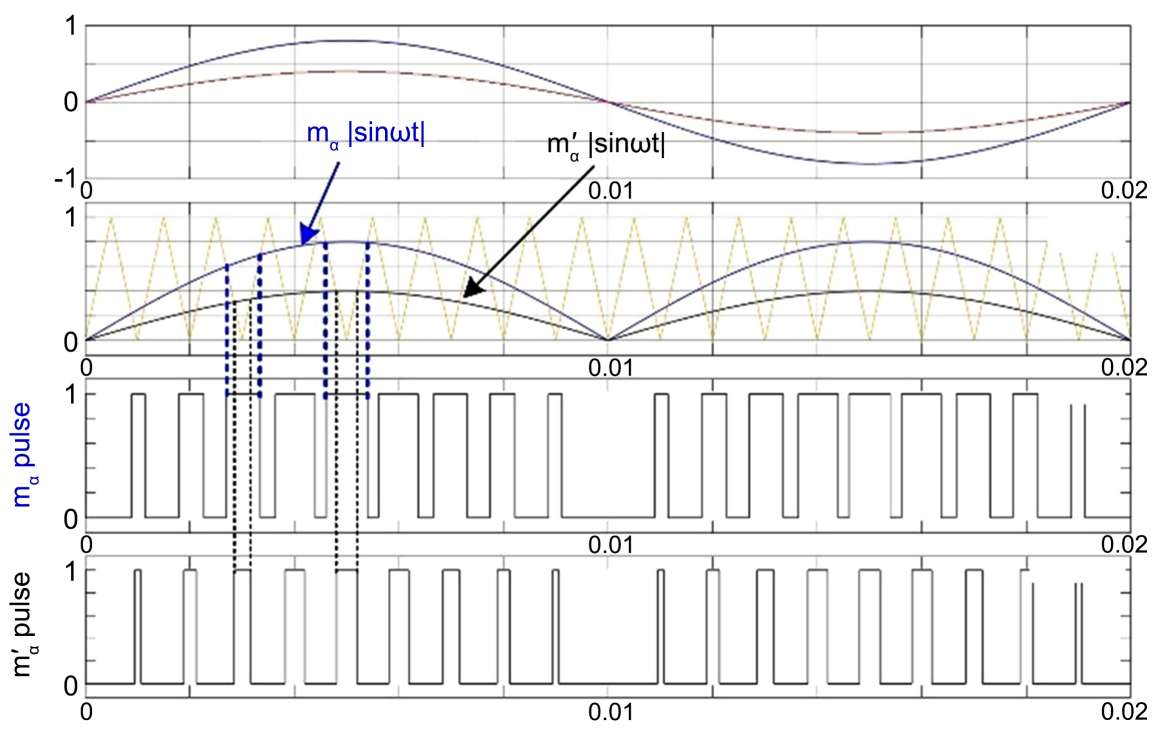

Figure 3. Pulse width modulation of switching device. Example of high (ma) and low (ma') modulation index.

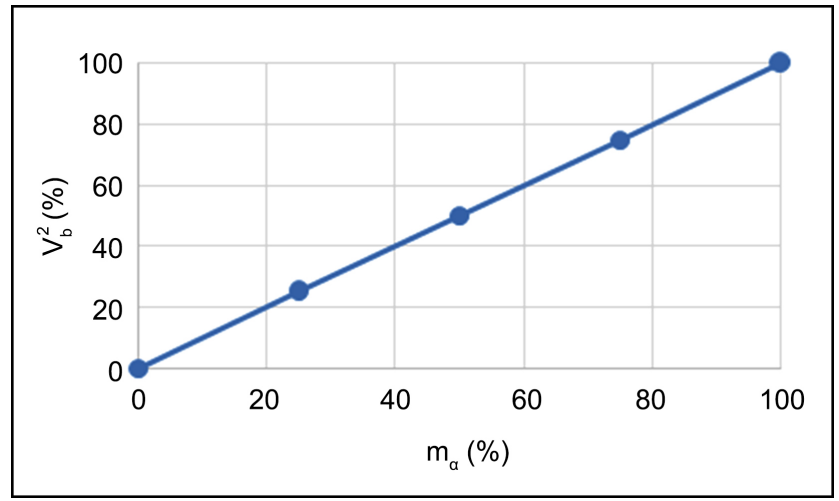

Figure 4. $V_{b}^{2}$ with respect to $m_{a} . V_{b}^{2}$ is calculated as a percentage of $V_{b}^{2}$ for $m_{a}=1$. 
It has to be noted here that $m_{a}>1$ is possible and it results to even higher $V_{b}^{2}$. However, a series of issues are raised which, even if they could be handled accordingly, they would confuse the reader with formulation and methodology beyond the main scope of this paper, which is to demonstrate the possible services provided by the Smart Boiler to the grid. The most important of those issues for $m_{a}>1$ connected with the content of this work, are the non-linear relationship between $m_{a}$ and $V_{b}^{2}$ and the alteration of expected harmonic content [12] [13]. By limiting $m_{a} \leq 1$ we keep the formulation and methodology simple, without jeopardizing the generality of the approach.

\subsection{Reactive Power Control}

The electric load contained in the boiler tank can be practically assumed as purely resistive. This means that a typical electric boiler does not produce or consume reactive power. However, the Smart Boiler has this capability by creating a phase difference between the fundamental current harmonic and the supplying voltage [14]. This can be achieved by making the sinewave lead or lag in comparison with a reference sinewave synchronized with the supplying AC voltage (Figure 5). When the sinewave is shifted, timewise, to the left, the fundamental harmonic of current leads in comparison to the voltage, thus, reactive power is injected to the grid. Similarly, when the sinewave is shifted to the right, reactive power is absorbed from the grid. If $\delta$ is the time shifting between fundamental current and voltage (usually expressed as an angle, using a complete voltage sinewave period as a $360^{\circ}$ reference), then the reactive power $Q$ injected or absorbed from the rectifier to the grid is given by the following equation:

$$
Q=V_{b}^{2} \sin \delta / R,
$$

where $R$ is the value of the heating resistor.

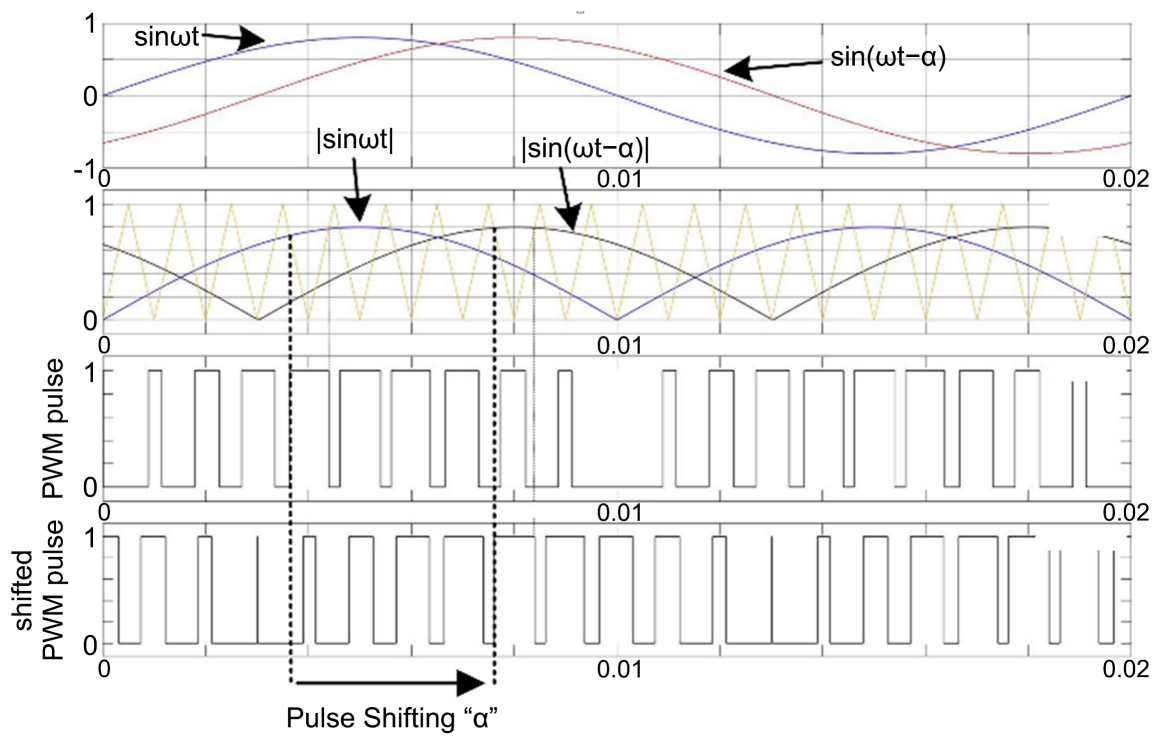

Figure 5. Pulse width modulation of switching device for shifting of rectifier's current funda-mental harmonic with respect to voltage. 
However, the resulting $\delta$ is not equal to the shifting angle of the modulation sinewave, named a hereafter. Figure 6 contains plots of $\delta$ with respect to a for different values of $m_{a}$. Clearly, $\delta$ resembles to a sinusoidal function of $a$, which is nearly unaffected by the chosen value for $m_{a}$ (see magnification in Figure 6). This function has a maximum of $+18^{\circ}$ and a minimum of $-18^{\circ}$ found for a equal to $+55^{\circ}$ and $-55^{\circ}$, respectively. Obviously, the extremes of $\delta$ are caused by the same values of $a$, indifferent of the chosen value for $m_{a}$. Furthermore, $\delta$ is mostly linear between its two extremes; a particular useful feature for robust control. However, it should not be assumed that these extremes provide the maximum and minimum reactive power for the rectifier. According to (2), $Q$ is also a function of $V_{b}^{2}$, which is affected by $\alpha$. The impact of $\alpha$ on $V_{b}^{2}$ for different values of $m_{a}$ is demonstrated in Figure 7. It can be easily noticed that there is a significant drop of $V_{b}^{2}$ for high values of $a$. Figure 8 contains $Q$ with respect to $a$ for

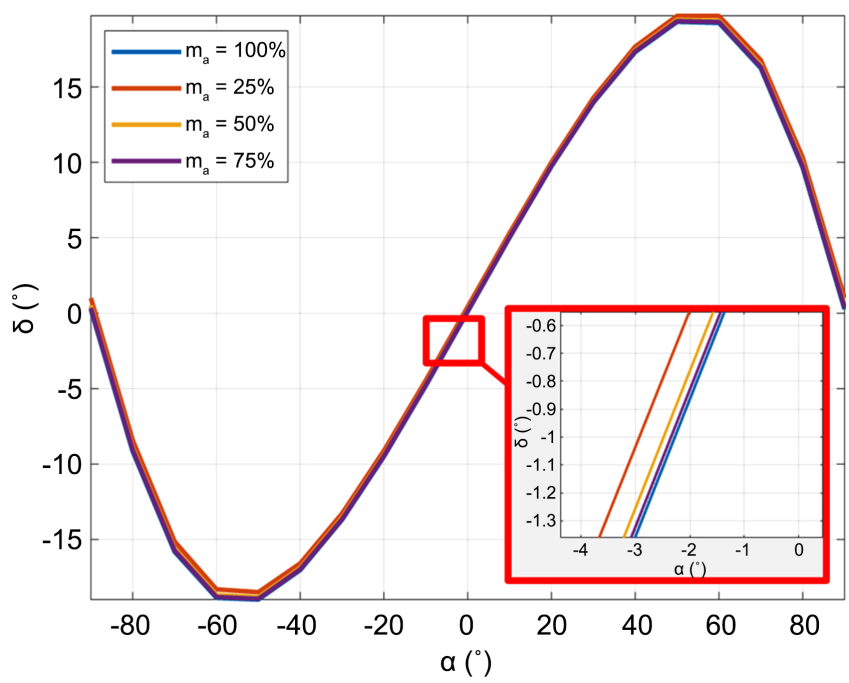

Figure 6. Angle $\delta$ with respect to a for different values of $m_{a}$.

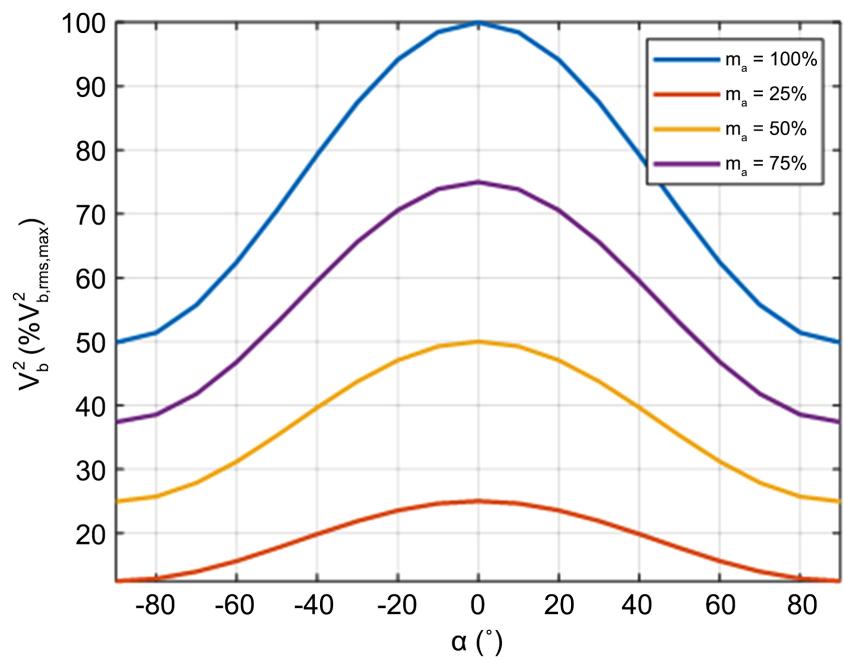

Figure 7. $V_{b}^{2}$ with respect to a for different values of $m_{a} \cdot V_{b}^{2}$ is calculated as a percentage of its maximum possible value (i.e. for $m_{a}=1, a=0^{\circ}$ ). 


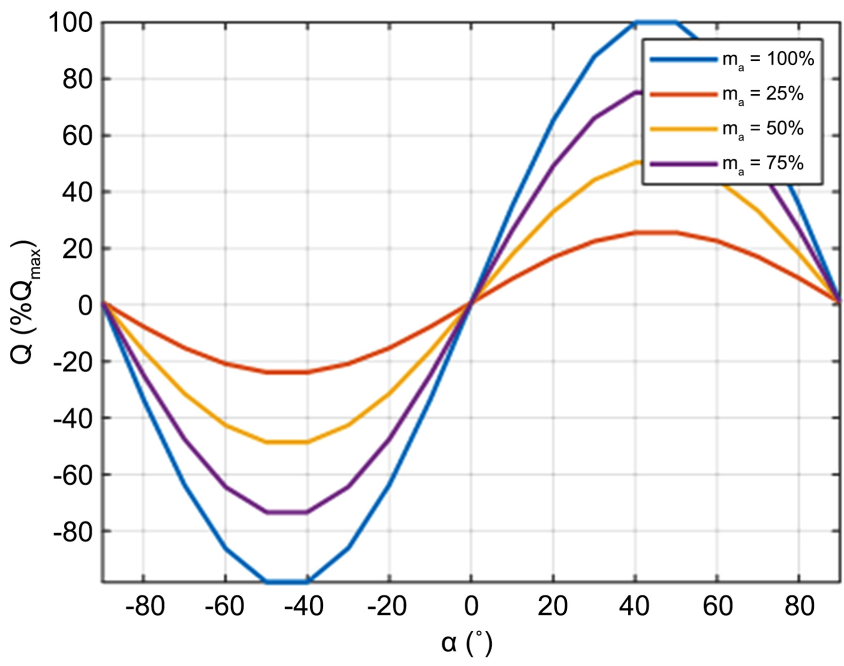

Figure 8. Q with respect to a for different values of $m_{a}$. $Q$ is calculated as a percentage of its maximum possible value (i.e. for $m_{a}=1, a=90^{\circ}$ ).

different values of $m_{a}$, by combining the results presented in Figure 6 and Figure 7 using (2). Maximum reactive power is produced for $a=+45^{\circ}$ and minimum reactive power is consumed for $a=-45^{\circ}$. It should be noted that if $a$ increases beyond $+45^{\circ}$, produced reactive power actually decreases. Similarly, if a decreases beyond $-45^{\circ}$, consumed reactive power also decreases. Therefore, if reactive power output of the Smart Boiler is to be controlled, a should be limited in the range of $\left[-45^{\circ},+45^{\circ}\right]$.

\subsection{Harmonic Compensation}

Distribution grids contain an increasing number of non-linear and switching loads, as well as, significant renewable generation interfacing through power converters. The result is that the harmonic content of the supplying line deteriorates, even below acceptable levels. It will be demonstrated that the Smart Boiler, without the use of additional equipment or passive filters, can suppress its own low order current harmonics, but also reduce line harmonics caused by other sources.

The main idea is that proper modulation will lead the converter to absorb current with a waveform that contains the suitable mirror harmonic content, resulting in line harmonic cancellation. More specifically, an FFT analysis of the distorted line current is performed. Mirror harmonics of that distortion, i.e. harmonics that have the same frequency and amplitude but a $180^{\circ}$ phase shift from it, are added to the sinewave during the pulse generation modulation. After the mirror harmonics injection, FFT is carried out again so that information about the alternation of the harmonic content is obtained and the mirror harmonics to be injected are recalculated. A brief mathematical formulation of this procedure is described below [15].

If line harmonic component at frequency $f=\omega t$ is $h_{A}(t)$ and the smart boiler injects a harmonic component $h_{B}(t)$, then total harmonic content would 
be $h_{C}(t)$. This would be:

$$
\begin{aligned}
& h_{A}(t)=A \sin (2 \pi f+a) \\
& h_{B}(t)=B \sin (2 \pi f+b) \\
& h_{C}(t)=C \sin (2 \pi f+c),
\end{aligned}
$$

in which $A, B, C$ and $a, b, c$ are the amplitudes and the phase angles of the aforementioned signals respectively. Because all these signals have the same frequency $f$, the previous functions can be converted into phasors:

$$
\begin{aligned}
h_{A} & =A \mathrm{e}^{j a} \\
h_{B} & =B \mathrm{e}^{j b} \\
h_{C} & =C \mathrm{e}^{j c} .
\end{aligned}
$$

However, the output harmonic content $C$ can be calculated with respect to components $A$ and $B$ by:

$$
C \mathrm{e}^{j c}=A \mathrm{e}^{j a}+B \mathrm{e}^{j b} .
$$

Therefore, amplitudes $A, B, C$ and phase angles $a, b, c$ are related with each other by the equations:

$$
\begin{aligned}
& A \cos a+j A \sin a+B \cos b+j B \sin b=C \cos c+j C \sin C, \text { thus, } \\
& C \cos c=A \cos a+B \cos b \text { and } C \sin c=A \sin a+B \sin b
\end{aligned}
$$

Solving (6) with respect to injecting harmonic amplitude $A$ and angle a gives:

$$
\begin{aligned}
& a=\tan ^{-1}[(C \sin c-B \sin b) /(C \cos c-B \cos b)] \\
& A=(C \cos c-B \cos b) / \cos a
\end{aligned}
$$

Obviously, during the initial iteration, no mirror harmonic is injected by the Smart Boiler's converter. This means that $B=b=0$, therefore, according to (7), $A=C$ and $\alpha=c$. FFT analysis of the line harmonic content ( $C$ and $c$ ) should be executed constantly, so that the Smart Boiler's converter responds immediately at any random change of harmonic content ( $\alpha$ and $A$ ). It has to be underlined that this method can be extended to more than one high-order harmonics simultaneously [16]. Figure 9 describes the process of creating the mirror harmonics during modulation.

\section{Modulation Implementation}

In this Section, the implementation of the Smart Boiler control is presented, so that specific grid support services are provided. It must provide active power control, reactive power control and harmonic compensation, simultaneously. As described in Section 3, all three control targets are fulfilled by appropriate modulation of its converter output by triggering the single switching element of the device. Therefore, the modulation waveform, which is compared with the carrier triangle for PWM, is created by the combined output of three distinct control subsystems (Figure 10). 


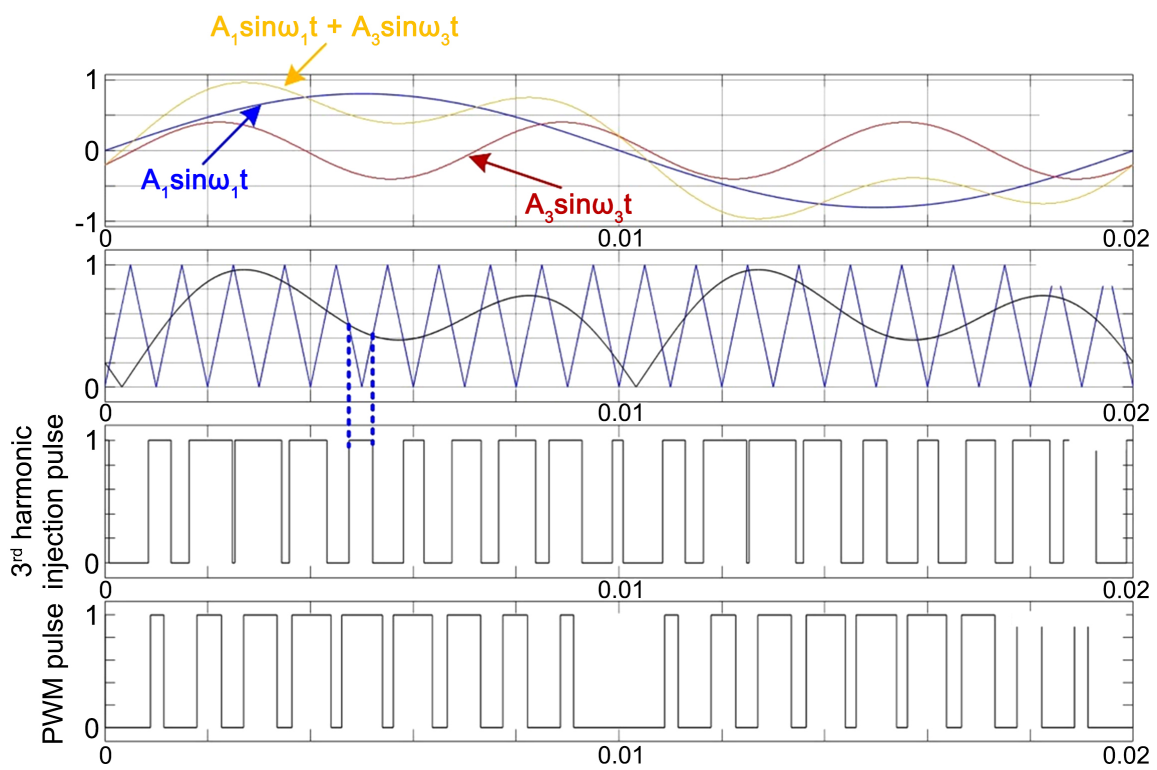

Figure 9. Creation of mirror harmonics by appropriate pulse width modulation of switching device.

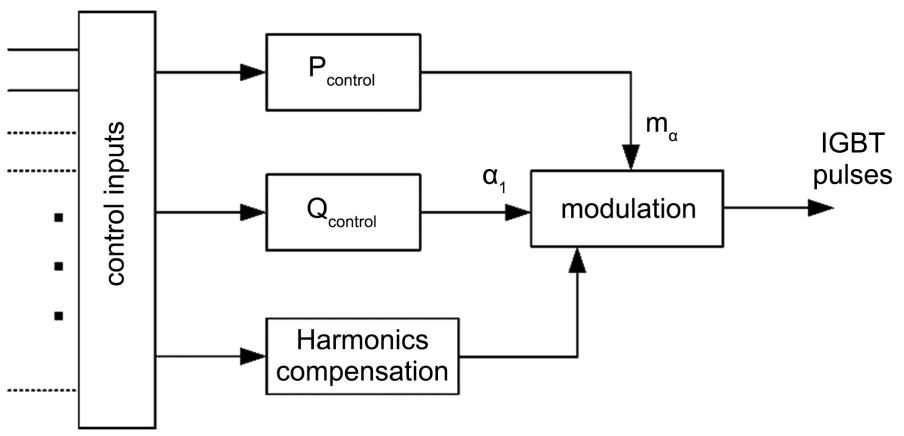

Figure 10. Creation of smart Boiler's converter modulation waveform from three, distinct, control subsystems.

Obviously, the Smart Boiler can provide the power quality services mentioned in Section 3, as long as it consumes active power to heat the water at a specific temperature. This requirement has been modeled in this work by switching off the converter of the Smart Boiler when a specific amount of electric energy is consumed $\left(E_{\text {required }}\right)$. In Figure 11, the implementation of the subsystem for active power control is presented. The control disturbance used as input depends on the actual target set by the smart grid operating guidelines or requirements set by the Smart Boiler owner. Here, a simple PI controller regulates the amount of active power consumed by the Smart Boiler (see Subsection 3.1), so that the voltage RMS value of the feeder bus $\left(V_{L}\right)$ is regulated to $230 \mathrm{~V}$. This specific control target may be proven useful for smart grids developed over LV distribution power networks, where the resistive characteristic of the lines prevails over the inductive, so there is a strong correlation between active power flow and terminal bus voltage. Indifferent of the disturbance used as control input the PI controller has to be equipped with anti-windup saturation capability for $m_{a}$ from 
0 to 1 for the reasons explained in Subsection 3.1. Theoretically, a higher upper limit could be used, but the effect of $m_{a}>1$ on the other two control subsystems has to be investigated and properly mitigated first. This is beyond the scope of this paper. In any case, the converter of the Smart Boiler switches off $\left(m_{a}=0\right)$, when the electric energy supplied to the resistor (integration of consumed active power $P_{L}$ over time) reaches $E_{\text {required }}$.

Since Smart Boilers cannot generate active power, this type of active power control can only reduce terminal voltage, but there are important applications even in this case. For example, during time of light load bus voltage levels increase, forcing grid operators to take their own control action in order to regulate voltages, such as continuously changing the tap ratio of distribution transformers or connecting/disconnecting reactive loads at MV buses. Some of these actions could be replaced by appropriate actions of the grid's Smart Boilers, reducing the investment and maintenance cost of the grid for the operator. Moreover, during time of light load electricity prices are usually lower, so it makes sense to warm-up water much cheaper during that time, while regulating terminal voltage. Of course, other control targets could be implemented by changing the reference and input signals. For instance, the active power consumption of the Smart Boiler could be optimized over time according to predicted future electricity prices, if the owner determines when he will actually need the hot water.

In Figure 12, the implementation of the reactive power control subsystem is presented. A simple PI controller regulates the reactive power consumed or produced by the Smart Boiler (see Subsection3.2), so that the feeder supplies as little reactive power as possible $\left(Q_{\text {set }}=0\right)$, i.e. providing power factor maximization that minimizes feeder current magnitude and losses. Of course, the Smart Boiler could follow a different reactive power management plan, centrally coordinated by the grid operator. For example, if the control input disturbance

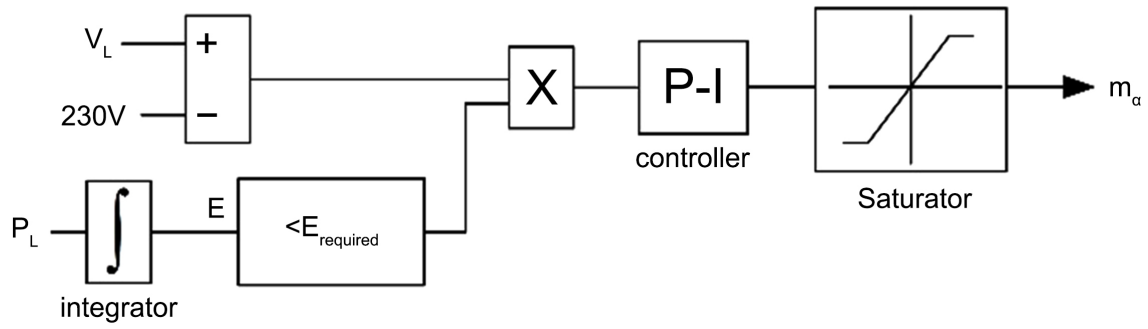

Figure 11. Implementation of the active power control subsystem for terminal bus voltage control.

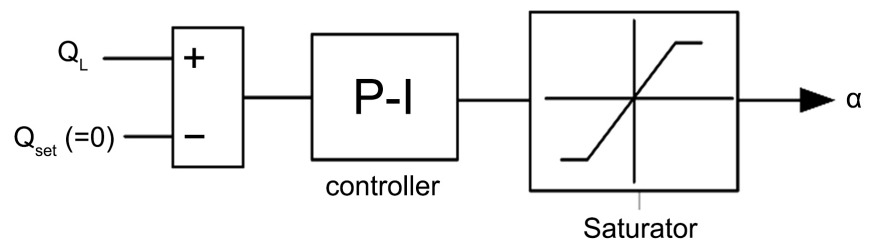

Figure 12. Implementation of the reactive power control subsystem for power factor maximization. 
changes to the diversion of the central MV bus voltage from nominal, measured and broadcasted from the grid operator, the Smart Boilers of all feeders could provide voltage support to the main MV supplying bus of the smart grid. In any case, the PI controller is equipped with anti-windup saturation capability for angle a from $-45^{\circ}$ to $+45^{\circ}$ for the reasons explained in Subsection 3.2.

It has to be clarified at this point, that PI control have been chosen for both the active and reactive power control subsystems, as one of the simplest and easier to parametrize control approaches available. Adaptive, fuzzy logic or any other type of more sophisticated control can be suggested instead, possibly with better performance. Optimizing the control response is not the scope of this paper, but it will certainly be an important part of future, separate work. However, judging from the simulation results presented in the next section, the control performance seems to be adequate.

In Figure 13(a), the implementation of the harmonic compensation control subsystem is contained. It performs an iterative procedure of mirror harmonics calculation and injection. First, an FFT analysis of the line current is performed. The output of the FFT analysis, magnitudes $\left(\left|I_{1}\right|,\left|I_{3}\right|, \cdots,\left|I_{n}\right|\right)$ and angles $\left(a_{1}, a_{3}, \cdots\right.$, $a_{\mathrm{n}}$ ) of all current harmonics to be compensated, is used as input to a block that implements (7). New mirror harmonics are calculated with respect to line harmonics from other sources and mirror harmonics currently injected according to the previous iteration. The result is used for the calculation and injection of new mirror harmonics and becomes the feedback for the next iteration, as currently injected harmonics. It has to be noted that the magnitude of mirror harmonics, before they are injected, has to be normalized with respect to the measured fundamental current component. This way the appropriate modulation index is calculated for each mirror harmonic, so that the correct harmonic current magnitude is produced. This is a logical conclusion, since the load of the electric heater does not change with frequency, as it has a purely resistive nature, therefore the resulting harmonic currents (including the fundamental component) are proportional to the respective harmonic modulation indexes.

Figure 13(b) presents a flowchart of the implementation of the harmonic compensation control subsystem (Figure 13(a)) in the form of an algorithm consisted of a sequence of processes. Each process is signified with a latin number, corresponding to the same number for each respective part of the implementation. The details of each process are detailed below:

1) Harmonic line currents are measured and analyzed with respect to their magnitude and angle $\left(C_{h}, c_{h}\right)$.

2) Equation (7) calculates "indigenous" harmonic currents that already exist in the line $\left(A_{h}, \alpha_{h}\right)$, that is harmonic line currents if there has not been any injection of mirror harmonics by the converter set by the previous iteration $\left(B_{h}, b_{h}\right)$. Please note that the calculated magnitude of indigenous harmonics is multiplied by -1 in (7), in order to accommodate the requirement for the production of mirror harmonics in the next process. 


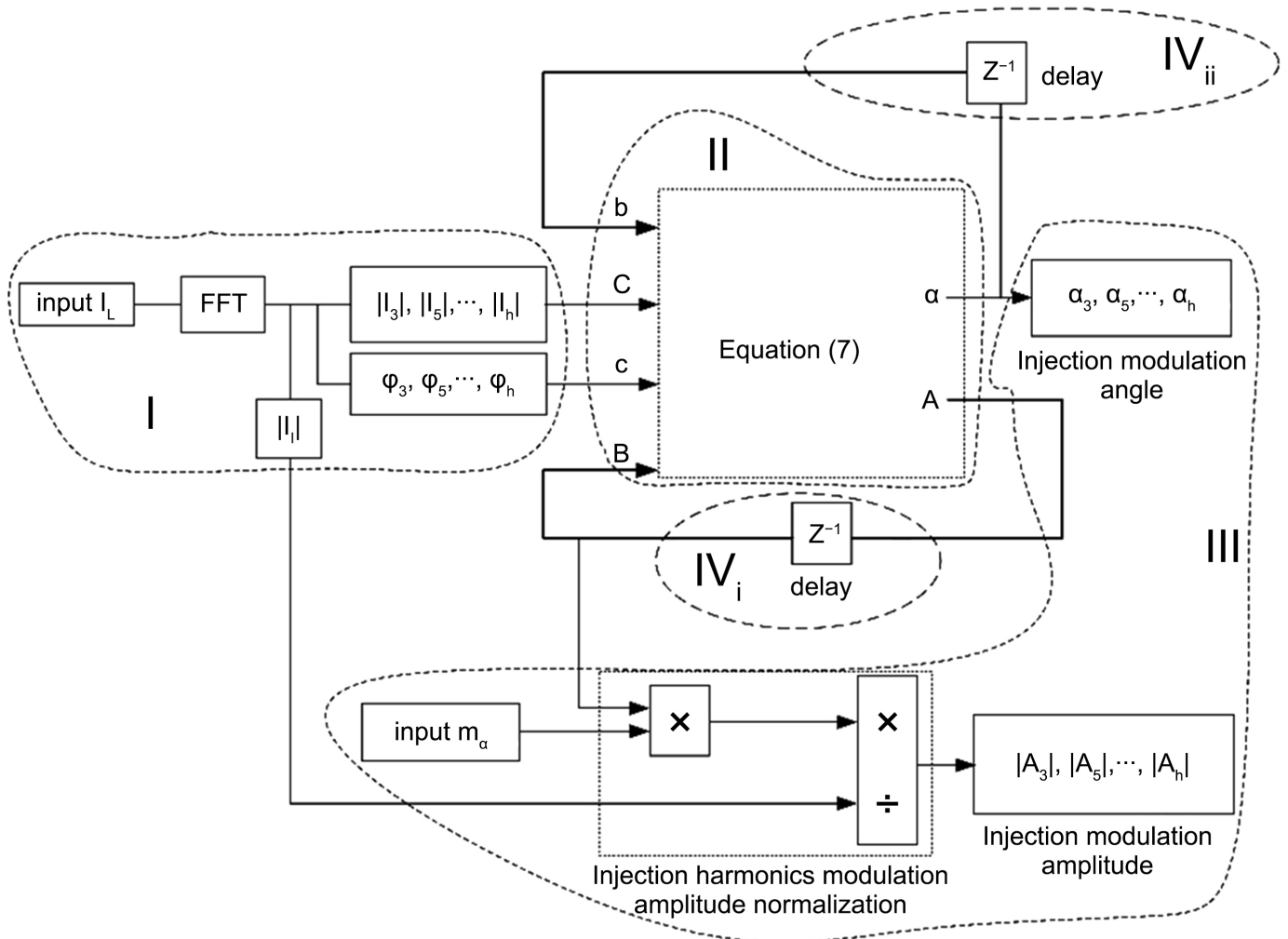

(a)

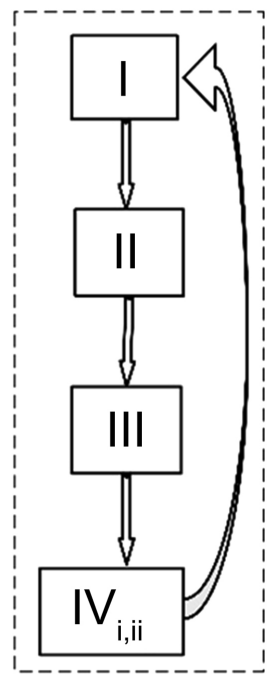

(b)

Figure 13. Harmonic compensation control subsystem: (a) Implementation; (b) Process-by-process algorithmic flowchart.

3) Mirror harmonics $\left(A_{h}, \alpha_{h}\right)$ are normalized with respect to the fundamental harmonic, as explained in the previous paragraph in more detail, and they are injected in the modulation signal of the converter. The injection process is graphically explained in Figure 9, using the injection of a 3rd harmonic as an example.

4) This process spreads in two places of Figure 13(a); one for phase angles (IVi) and one for amplitudes (IVii) of harmonic currents. However, they can be considered parts of the same process, as calculated mirror harmonics $\left(A_{h}, \alpha_{h}\right)$ are stored in control memory as "existing" injected harmonics $\left(B_{h}, b_{h}\right)$, so that they can be considered for the calculation of "indigenous" harmonics in the next repetition. As soon as this is done, the execution sequence returns to process I.

\section{Verification and Operation}

In this Section, the capability of the Smart Boiler to offer significant power quality services to the smart grid, will be demonstrated.

\subsection{Test Case Description}

Figure 14 presents the oneline diagram of the distribution system, where the power quality services of the Smart Boilers will be simulated. The system connects to the grid, which is simulated as an infinite bus noted as "Bus", via a MV line. The MV line terminates at a step-down transformer, which, for the simplicity 


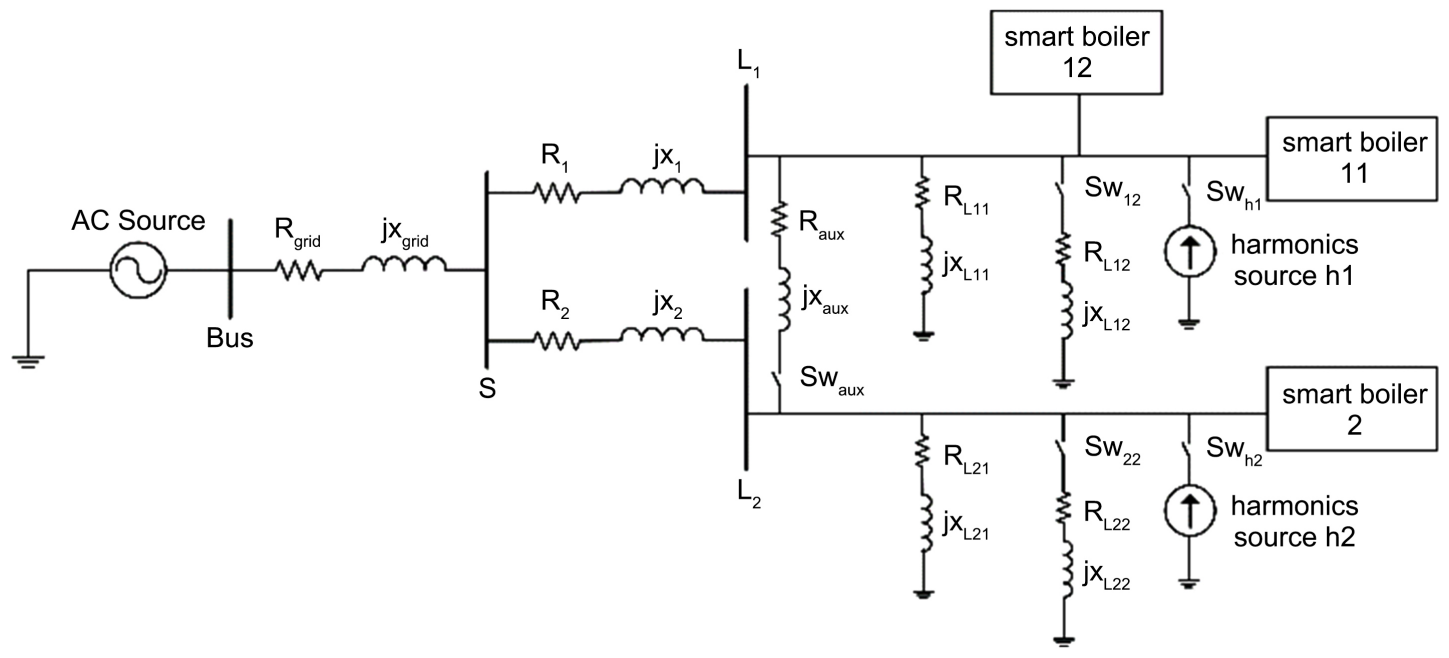

Figure 14. Distribution system used as a test case for Smart Boilers.

of the simulation, has characteristics augmented at the MV line characteristics $\left(\mathrm{R}_{\text {grid }}+\mathrm{j} \mathrm{X}_{\text {grid }}\right)$. It supplies power to two LV feeder lines starting at bus $\mathrm{S}$. The first terminates at bus $L_{1}\left(R_{1}+j X_{1}\right)$ and the second at bus $L_{2}\left(R_{2}+j X_{2}\right)$. The load group at bus $\mathrm{L}_{1}$ consists of a permanent mixed load of constant impedance $\left(\mathrm{R}_{\mathrm{L} 11}\right.$ $\left.+\mathrm{JX}_{\mathrm{L} 11}\right)$, a constant impedance mixed load $\left(\mathrm{R}_{\mathrm{L} 12}+\mathrm{JX}_{\mathrm{L} 12}\right)$ connected via switch $\mathrm{Sw}_{12}$, a source of harmonic currents (named harmonic source-h1) simulated as a source drawing currents at specific frequencies and phase angles when $\mathrm{Sw}_{\mathrm{h} 1}$ is closed and two Smart Boilers. The load group at bus $\mathrm{L}_{2}$ adds up to a permanent mixed load of constant impedance $\left(\mathrm{R}_{\mathrm{L} 21}+\mathrm{JX}_{\mathrm{L} 21}\right)$, a constant impedance mixed load $\left(\mathrm{R}_{\mathrm{L} 22}+\mathrm{JX}_{\mathrm{L} 22}\right)$ connected via switch $\mathrm{Sw}_{22}$, a source of harmonic currents (named harmonic source-h2) simulated as a source drawing currents at specific frequencies and phase angles when $\mathrm{Sw}_{\mathrm{h} 1}$ is closed and one Smart Boiler. Finally, there is an auxiliary line $\left(\mathrm{R}_{\text {aux }}+\mathrm{JX}_{\text {aux }}\right)$ connecting terminal buses $\mathrm{L}_{1}$ and $\mathrm{L}_{2}$ of the two line feeders, when switch $\mathrm{Sw}_{\text {aux }}$ is closed. The connection and disconnection of the auxiliary line simulates possible network topology changes at various locations of the smart grid, due to switching actions required by maintenance or fault clearance.

Table 1 contains the values of the aforementioned load and line impedances. At no load, feeder voltages reach $240 \mathrm{~V}$, which is the nominal voltage at the low voltage side of the step-down transformer, so that during average loading, voltages at the line feeders drop near the ideal $230 \mathrm{~V}$ for electric appliances. Loads in our simulated case, permanent and switchable, simulate a period of generally light loading for the system, so that the operation of the Smart Boilers becomes more practical (see Section 4).

Initially, the Smart Boilers will be considered idle, so that the impact of a sequence of events on the quality of the related system properties can be recorded. Then, the record of those properties will be compared to the properties recorded under the same sequence of events, but with the smart boilers activated. This way, the operation of Smart Boilers can be assessed. Table 2 includes this se- 
quence of events. On both line feeders there are significant load changes, injections of harmonic currents at different magnitudes and phase angles, and a significant change of their impedance characteristics by the activation/deactivation of the auxiliary line. The time difference between events is chosen in such a way, so that it is sufficiently long for the system to reach a new steady state between events (with or without the Smart Boilers activated), but short enough for the overall sequence of events to fit in a short time scale (in the order of seconds).

Table 1. Values of load and line impedances of the simulated distribution system used as a test case for the operation of Smart Boilers.

\begin{tabular}{ccc}
\hline Type/name & Specified values & Values \\
MV line & $\mathrm{R}_{\text {grid }}+\mathrm{j} \mathrm{X}_{\text {grid }}$ & $0.1+\mathrm{j} 0.85 \Omega$ \\
LV line feeder 1 & $\mathrm{R}_{1}+\mathrm{j} \mathrm{X}_{1}$ & $0.53+\mathrm{j} 0.07 \Omega$ \\
LV line feeder 2 & $\mathrm{R}_{2}+\mathrm{j} \mathrm{X}_{2}$ & $0.8+\mathrm{j} 0.1 \Omega$ \\
Auxiliary line & $\mathrm{R}_{\mathrm{aux}}+\mathrm{JX}_{\mathrm{aux}}$ & $0.27+\mathrm{j} 0.03 \Omega$ \\
Perm. load $\mathrm{L}_{11}$ & $\mathrm{R}_{\mathrm{L} 11}+\mathrm{J} \mathrm{X}_{\mathrm{L} 11}$ & $72.25+\mathrm{j} 15.48 \Omega$ \\
Perm. load $\mathrm{L}_{21}$ & $\mathrm{R}_{\mathrm{L} 21}+\mathrm{JX}_{\mathrm{L} 21}$ & $144.5+\mathrm{j} 30.96 \Omega$ \\
Non-perm. load $\mathrm{L}_{12}$ & $\mathrm{R}_{\mathrm{L} 12}+\mathrm{JX}_{\mathrm{L} 12}$ & $72.25+\mathrm{j} 15.48 \Omega$ \\
Non-perm. load $\mathrm{L}_{22}$ & $\mathrm{R}_{\mathrm{L} 22}+\mathrm{J} \mathrm{X}_{\mathrm{L} 22}$ & $144.5+\mathrm{j} 30.96 \Omega$ \\
Harm. source h1 & Order, $\left|\mathrm{I}_{\mathrm{h}}\right|, \varphi_{\mathrm{h}}$ & $3^{\text {rd }} .3 \mathrm{~A} .-60^{\circ}$ \\
Harm. source h2 & Order, $\left|\mathrm{I}_{\mathrm{h}}\right|, \varphi_{\mathrm{h}}$ & $3^{\text {rd }} .2 \mathrm{~A} .30^{\circ}$ \\
\hline
\end{tabular}

Table 2. Sequence of events for the test case.

\begin{tabular}{|c|c|c|}
\hline Event & Type (location) & Time \\
\hline Sw12 $_{12}$ closes & Load increment (feeder 1) & $1.2 \mathrm{~s}$ \\
\hline $\mathrm{Sw}_{22}$ closes & Load increment (feeder 2) & $2.4 \mathrm{~s}$ \\
\hline Swhl closes & Harmonic injection (feeder 1) & $3.6 \mathrm{~s}$ \\
\hline Swaux closes & Reconfiguration (feeders) & $4.8 \mathrm{~s}$ \\
\hline Swh2 closes & Harmonic injection (feeder 2) & $6.0 \mathrm{~s}$ \\
\hline Sw12 opens & Load decrement (feeder 1) & $7.2 \mathrm{~s}$ \\
\hline $\mathrm{Sw}_{22}$ opens & Load decrement (feeder 2) & $8.4 \mathrm{~s}$ \\
\hline Swh1 opens & Harmonic stops (feeder 1) & $8.4 \mathrm{~s}$ \\
\hline Swaux opens & Reconfiguration (feeders) & $9.6 \mathrm{~s}$ \\
\hline Swh2 opens & Harmonic stops (feeder 2) & $10.8 \mathrm{~s}$ \\
\hline
\end{tabular}




\subsection{Power Quality Properties with Smart Boilers Idle}

In Figure 15, the impact of the sequence of events (Table 2) on system power quality properties is presented, assuming that Smart Boilers are kept idle. Throughout the simulation time, light loading results to significantly higher RMS voltage levels at feeders, than the ideal voltage for sensitive electric appliances of $230 \mathrm{~V}$. As expected, load changes at events 1,2, 6, 7 and network reconfigurations at events 4, 9 affect supplied RMS voltages at feeders, significantly (Figure 15(a)). Significant reactive power also flows through the line feeders (Figure 15(b)). Excessive current harmonics in both line feeders are measured during the time that harmonic sources are connected. Figure 15(c) and Figure 15(d) present the RMS value of the $1^{\text {st }}, 3^{\text {rd }}$ and $5^{\text {th }}$ current harmonic for line feeder 1 and 2 , respectively. $5^{\text {th }}$ harmonic is measured, even if it is not injected in the grid by any source in this case, because later it will be compared with the $5^{\text {th }}$ harmonic created by the operation of the Smart Boilers. Harmonics higher than the order of 5 will be neglected, due to their insignificant value, without loss of generality of the approach for simultaneous compensation of any harmonic order by the Smart Boilers (see Section 3).

\subsection{Power Quality Properties with Smart Boilers Activated}

Smart Boilers can improve power quality in a distribution system as long as water is heated for their user. In Figure 16, the impact of the same sequence of

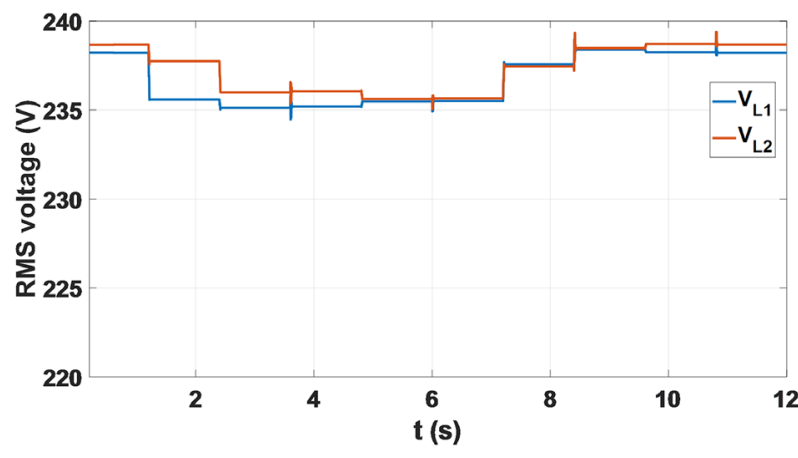

(a)

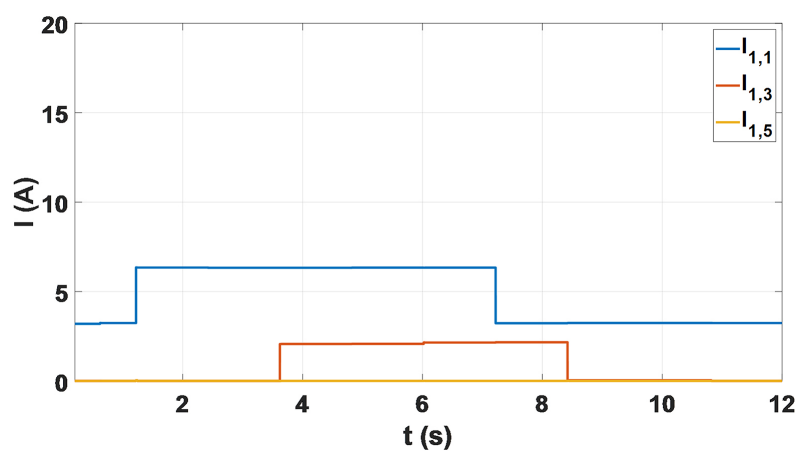

(c)

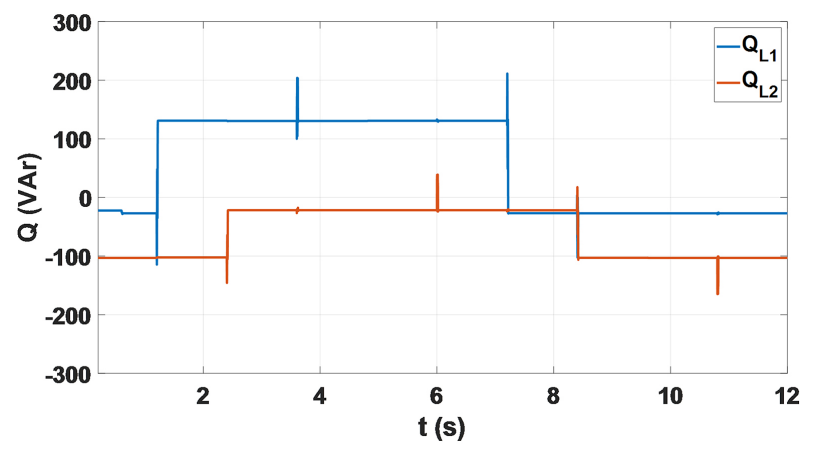

(b)

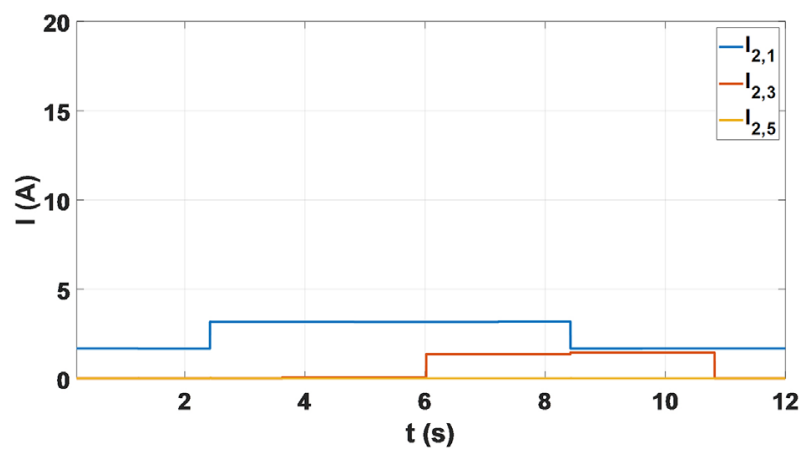

(d)

Figure 15. Smart Boilers inactive: impact of the sequence of events on power quality properties. (a) Voltages at terminal buses; (b) Reactive power at feeders; (c) Current harmonic content of feeder 1; (d) Current harmonic content of feeder 2. 


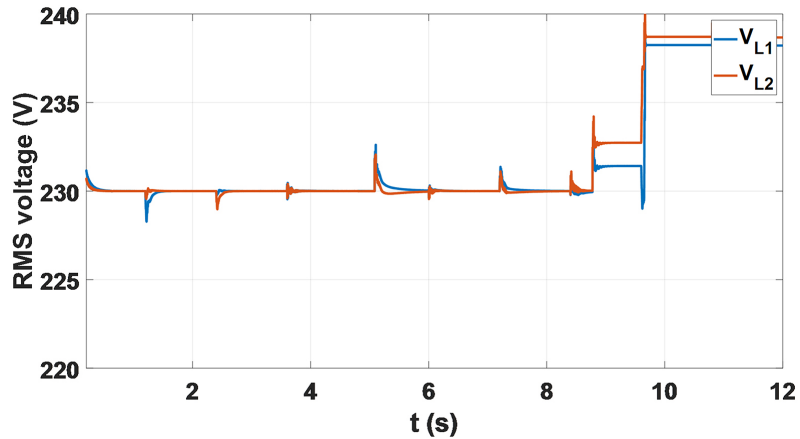

(a)

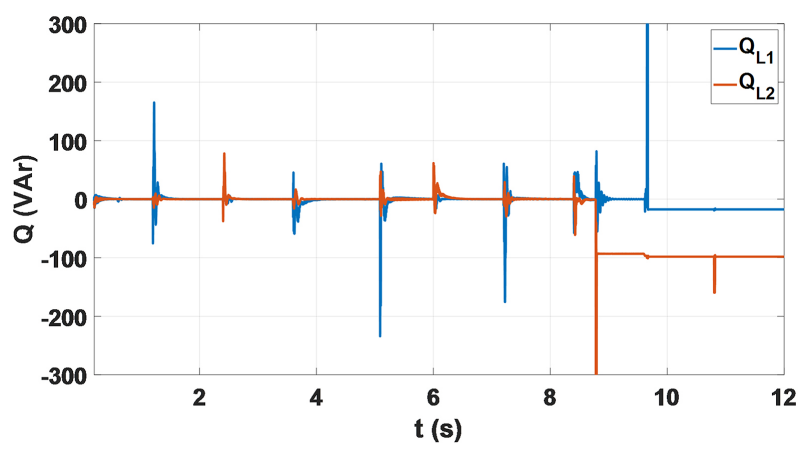

(c)

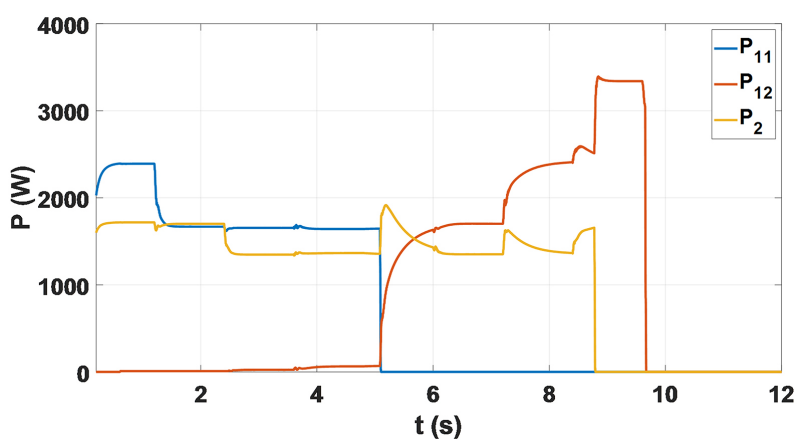

(b)

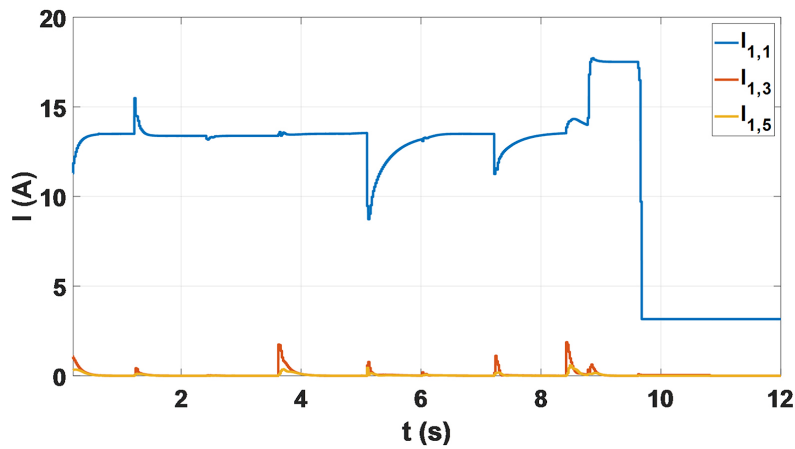

(d)

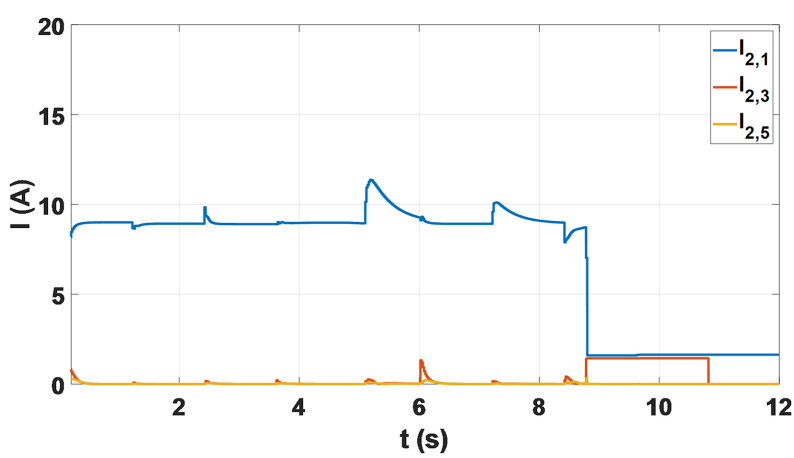

(e)

Figure 16. Smart Boilers activated: impact of the sequence of events on power quality properties. (a) Voltages at terminal buses; (b) Active power consumed by the Smart Boilers; (c) Reactive power at feeders; (d) Current harmonic content of feeder 1; (e) Current harmonic content of feeder 2 .

events (Table 2) on power quality properties is recorded, but this time Smart Boilers are activated. As it is depicted in Figure 14, there are two Smart Boilers connected to feeder 1 and one Smart Boiler to feeder 2. However, each Smart Boiler in a system is expected to consume different amounts of energy, due to different sizes of water tanks, different water temperatures at the beginning of the heating process and requested temperature at the end etc. This will be roughly simulated by setting different values to $\mathrm{E}_{\text {required }}$ of each Smart Boiler in the test case. More specifically, for Smart Boiler 11, Smart Boiler 12 and Smart Boiler 2, $\mathrm{E}_{\text {required }}$ is set equal to $9 \mathrm{kWs}, 10 \mathrm{kWs}$ and $13 \mathrm{kWs}$, respectively. Smart Boilers are expected to be activated at different points in time from their users. This is simulated by Smart Boiler 12 being activated with a delay of $0.6 \mathrm{~s}$ after the begin- 
ning of simulation time. All Smart Boilers are assumed to be "upgraded" electric boilers with typical $12.5 \Omega$ resistors. This means that before the "upgrade" water could be heated at a ratio of $4.2 \mathrm{~kW}$ for a $230 \mathrm{~V}$ supply voltage.

A typical switching frequency of $20 \mathrm{kHz}$ has been chosen for the power converters of the Smart Boilers. A $10 \mathrm{uF}$ high-frequency capacitor is installed at the AC input of the converter. This shunt capacitance, together with the inherent series inductance L of the feeders, create a basic LC passive filter for high order harmonics. Good dynamic control response has been achieved by setting $\mathrm{K}_{\mathrm{p}}=$ $0.05, K_{i}=2$ for the active and $K_{p}=0.1, K_{i}=2$ for the reactive power PI controller. For the control targets tested, three measuring devices must be connected at the terminal bus of each feeder and broadcast their measurements to the respective Smart Boilers: a Voltmeter, a VAr meter and a current harmonic analyzer.

In Figure 16, the impact of the sequence of events on system power quality properties and the operation of the Smart Boilers is presented. In Figure 16(a), it can be noticed that RMS voltages at both terminal buses are regulated at $230 \mathrm{~V}$ until $8.4 \mathrm{~s}$. According to Figure 16(b), this is the time that the Smart Boiler at feeder 2 seizes operation because its $E_{\text {required }}$ is reached, so there is nothing to regulate voltage at that feeder anymore. Voltage levels increase further at $9.7 \mathrm{~s}$, when this is the case for all three Smart Boilers. Between $8.4 \mathrm{~s}$ and $9.7 \mathrm{~s}$, Smart Boiler 12, the only activated Smart Boiler during this period, reaches a maximum power of $3.4 \mathrm{~kW}$. This is far below $4.2 \mathrm{~kW}$, the water heating power, which could be provided by the electric boiler before its "upgrade". The explanation is that the total RMS current fed into the Smart Boilers increases significantly, due to the other power quality services (reactive power control and harmonic compensation). It will become evident later on, when harmonic compensation control for all Smart Boilers will be deactivated (see Figure 17 and relevant comments below).

Successful reactive power control is also evident on both feeders. It is clear from Figure 16(c), that reactive power flow is kept to zero at the feeder, as long as there is at least one active Smart Boiler at that feeder. This is the case for feeder 2 till $8.4 \mathrm{~s}$ and for feeder 1 till $9.7 \mathrm{~s}$. Furthermore, harmonic currents are fully compensated at feeder1 (Figure 16(d)), because there is at least one Smart Boiler in operation at that feeder until the respective harmonic source is disconnected. This is not the case for the harmonic currents at feeder 2 (Figure 16(e)). Smart Boiler 2 reached its $\mathrm{E}_{\text {required }}$ limit at $8.4 \mathrm{~s}$, before harmonic source 2 is disconnected at $10.8 \mathrm{~s}$, according to the sequence of events of Table 2. The harmonic "surges" monitored at the beginning of each event can be explained by the respective change of current angle phase (due to load or network change) or the superposition of more than one harmonic (between 6 and 8.4 s). Smart Boilers, though, quickly adjust their mirror harmonics in order to compensate for those changes. It has to be noted that during steady state, harmonic current components are practically nullified, dropping below $0.05 \mathrm{~A}$ after any event.

At this point, it is important to underline the fact that Smart Boilers not only 
compensate the harmonic currents injected by the harmonic sources of the system, but also their own low order harmonics. In order to demonstrate the significance of those harmonic currents produced by the operation of the Smart Boiler converter, Figure 17 has been created. In this figure, the harmonic currents of feeder 1 (Figure 17(a)) and feeder 2 (Figure 17(b)) are measured, for the same sequence of events, but with the harmonic compensation control of the Smart Boilers deactivated. In this case, Smart Boilers attain the same level of success at regulating voltage and compensating reactive power at feeders. The performance is nearly identical to that presented in Figure 16(a) and Figure 16(c), so they should not be repeated here, due to space limitations. The only noticeable difference is found between 8.4 and $9.7 \mathrm{~s}$, that Smart Boiler 12 now reaches a maximum of $3.6 \mathrm{~kW}$, higher than the $3.4 \mathrm{~kW}$ reached with harmonic compensation control activated (see Figure 16(b)). This is an expected result for the available active power of the Smart Boiler, since some of its combined power headroom is released with the deactivation of harmonic compensation. Nevertheless, the harmonic content of both line feeders is much higher, now, throughout the simulation time, and there is a measurable $5^{\text {th }}$ order current component, too. This significant current harmonic content is produced by the operation of Smart Boilers, if their harmonic compensation control is deactivated.

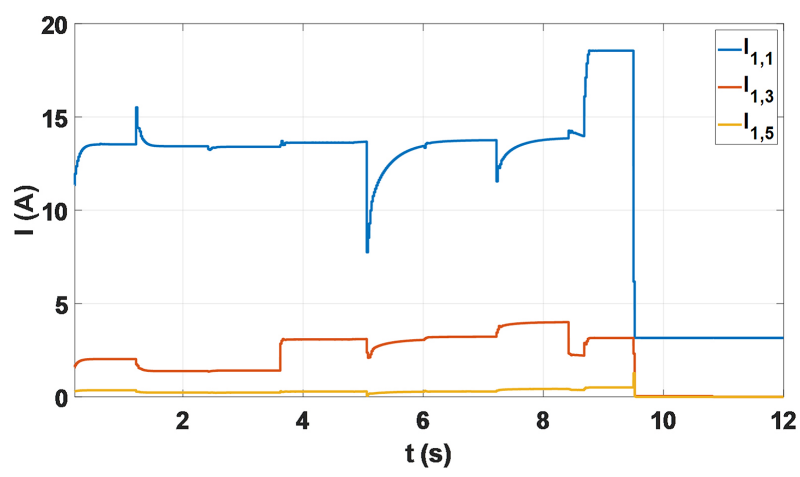

(a)

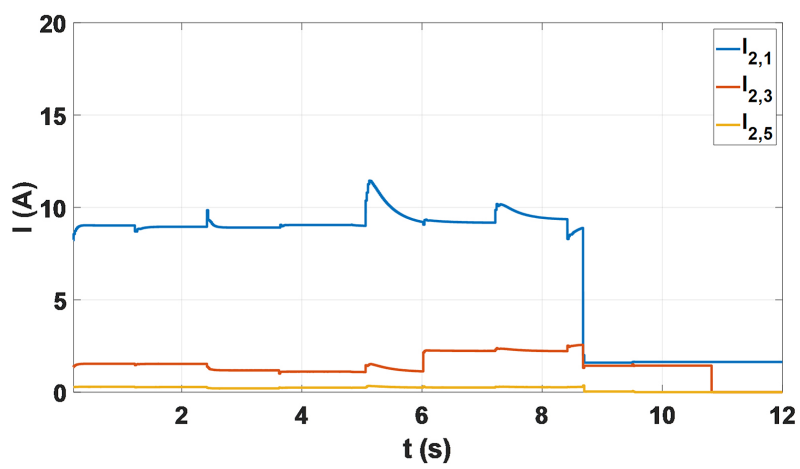

(b)

Figure 17. Smart Boilers activated, with harmonic compensation deactivated: (a) Current harmonic content of feeder 1; (b) Current harmonic content of feeder 2. 


\section{Alternative Applications and Future Work}

This work focuses on demonstrating the operational capabilities and performance of the suggested upgrade device, that will convert simple electric boilers to Smart Boilers. However, there are thermal loads in domestic or even industrial use, that could also be upgraded using, in concept, the same devices. Fossil fueled boilers used for central heating could also be upgraded to Smart Boilers by retrofitted resistors or the addition of secondary electric boilers. Then, the excess electric power provided by RES during periods of time that generation is greater than demand could be absorbed by the central heating systems, reducing fuel costs and bringing the energy performance of older buildings closer to the Nearly Zero Energy Building requirements.

Another possible application can be the interconnection of Smart Boilers to an EMS system that optimizes net-metering performance of RES prosumers. Monthly or quarterly energy surpluses could be "wisely" spent in water heating for domestic use or central heating, so that they are not given for free to the grid operator at the end of the clearing period (yearly or triennially). Of course, proper optimization would require adequate demand and RES-generation forecasting, as well as, proper consideration of the specific financial and technical regulations of net-metering set by the local energy authorities.

Smart Boilers can become one of the standards for domestic water heating. The reason is that if they are widely spread over the grid, aggregately, they could become an excellent tool for the grid operator without compromising the comfort of the users. However, the grid operator must have appropriate tools in order to continually evaluate their thermal headroom, estimate the impact of their operation on the grid and coordinate their action by distributing appropriate service requests to each one of them. That would require a telecommunication platform over which information between the Smart Boilers and the grid operator could be exchanged, but mostly, the design of a new compensation scheme for the amount and quality of grid services provided. Such platforms exist for the control of significant loads connected to MV and HV grids. The creation of a clustering method for Smart Boilers would allow similar platforms to be developed for LV grid operators or the Smart Grid.

The services provided to the grid by the possible applications of Smart Boilers, extend far beyond DSM and its expected value. Voltage support, reactive power control and harmonic suppression are power quality services for Smart Grids and LV networks in general, yet to be properly assessed before they are monetized. This paper is the first paper, proving the concept and indicating some of the possible future applications. It is the target of future work to assess the social and economic value of a possible widespread use of Smart Boilers and their alternative applications.

\section{Conclusions}

In this work, it has been shown how typical electric boilers can be upgraded, easily and with little cost, to smart devices that offer significant power quality services to the grid. As long as water needs to be heated, Smart Boilers can precisely 
control power consumed for heating, thus heating rate. Simultaneously, they can produce/consume reactive power and compensate low order current harmonics at the feeder indifferent of their source. Simulations have demonstrated the possibility these controls to be utilized by the smart grid operator for feeder voltage regulation, power factor correction and current compensation of multiple harmonic current sources. Alternative control targets have also been suggested. Of course, control targets depend on the required level of services by the Smart Grid and the available measuring sensors (see Section 6).

Future work will expand, but not be limited, to the investigation of possible interactions between control loops, coordination of Smart Boilers with other Smart Boilers or devices of the Smart Grid for improved services, as well as, grid losses minimization. Finally, the development and testing of prototypes is needed. Those prototype should be compatible with different grid properties (line R/X characteristics, loop circuits etc.) and operating conditions (voltages, harmonics etc.), so that the validity of the suggested model can be examined.

\section{Conflicts of Interest}

The authors declare no conflicts of interest regarding the publication of this paper.

\section{References}

[1] GFK Belgium Consortium (2017) Residential Prosumers in the European Energy Union. European Commission. https://ec.europa.eu/commission

[2] Miceli, R., Favuzza, S. and Genduso, F. (2013) A Perspective on the Future of Distribution: Smart Grids, State of the Art, Benefits and Research Plans. Energy and Power Engineering, 5, 36-42. https://doi.org/10.4236/epe.2013.51005

[3] Nikolaidis, P. and Poullikkas, A. (2017) A Comparative Review of Electrical Energy Storage Systems for Better Sustainability. Journal of Power Technologies, 97, 220-245.

[4] Elliman, R., Gould, C. and Al-Tai, M. (2015) Review of Current and Future Electrical Energy Storage Devices. Proceedings of the 50 th International Universities Power Engineering Conference (UPEC), Stoke-on-Trent, 1-4 September 2015, 1-5. https://doi.org/10.1109/UPEC.2015.7339795

[5] Australian Regulatory Authority (2017) Demand Management Incentives. Canberra.

[6] Cui, Q., Wang, X., Wang, X. and Zhang, Y. (2016) Residential Appliances Direct Load Control in Real-Time Using Cooperative Game. IEEE Transactions on Power Systems, 31, 226-233. https://doi.org/10.1109/TPWRS.2015.2391774

[7] Klaassen, E., Zhang, Y., Lampropoulos, I. and Slootweg, H. (2012) Demand Side Management of Electric Boilers. 3rd IEEE PES Innovative Smart Grid Technologies Europe (ISGT Europe), Berlin, 14-17 October 2012, 1-6. https://doi.org/10.1109/ISGTEurope.2012.6465681

[8] Kaegi, E., Berner, D. and Peter, A. (2011) Flexible Thermal Load Management for Ancillary Services Market: Experience of Swiss Smart Grid Pilot Project. 21 st International Conference on Electricity Distribution (CIRED), Frankfurt, 6-9 June 2011.

[9] Gheorghe, S., Golovanov, N., Lazaroiu, G. and Porumb, R. (2017) Smart Grid, Integration of Renewable Sources and Improvement of Power Quality. 21 st Interna- 
tional Conference on Control Systems and Computer Science (CSCS), Bucharest, 7 July 2017, 641-645. https://doi.org/10.1109/CSCS.2017.98

[10] Shen, J., Jiang, C. and Li, B. (2015) Controllable Load Management Approaches in Smart Grids. Energies, 8, 11187-11202. https://doi.org/10.3390/en81011187

[11] Serban, I. and Ion, C.P. (2016) Supporting the Dynamic Frequency Response in Microgrids by Means of Active Loads. 42nd Annual Conference of the IEEE Industrial Electronics Society (IECON), Florence, 23-26 October 2016, 3781-3786. https://doi.org/10.1109/IECON.2016.7793493

[12] Holmes, D.G. and Lipo, T.A. (2003) Pulse Width Modulation for Power Converters: Principles and Practice. IEEE Press, Piscataway. https://doi.org/10.1109/9780470546284

[13] Stojan, D. and Milanovič, M. (2010) Over-Modulation Phenomena and Its Influence on the Pulse Width Modulated Single-Phase Inverter Output Voltage. Automatika, 51, 174-180. https://doi.org/10.1080/00051144.2010.11828369

[14] Bauer, J. (2008) Single-Phase Pulse Width Modulated Rectifier. Acta Polytechnica, 48, 84-87.

[15] Bouloumpasis, I.D., Vovos, P.N., Georgakas, K.G. and Vovos, N.A. (2016) Harmonic Cancellation of PV-Supplied DC/AC Converter without Stabilizing Input Capacitors. IFAC-PapersOnLine, 49, 35-40. https://doi.org/10.1016/j.ifacol.2016.10.698

[16] Georgakas, K.G., Vovos, P.N. and Vovos, N.A. (2014) Harmonic Reduction Method for a Single-Phase DC-AC Converter without an Output Filter. IEEE Transactions on Power Electronics, 29, 4624-4632. https://doi.org/10.1109/TPEL.2013.2286918 